\title{
A scoping review of the changing landscape of geriatric medicine in undergraduate medical education: curricula, topics and teaching methods
}

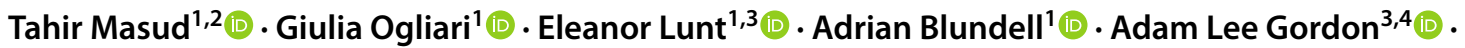 \\ Regina Roller-Wirnsberger ${ }^{5}$ (i) $\cdot$ Michael Vassallo $^{6}$ (D) Daniela Mari ${ }^{7}$ (D) Marina Kotsani ${ }^{8,9}$ (D) Katrin Singler $^{10,11}$ (D) \\ Roman Romero-Ortuno ${ }^{12}\left(\right.$ D . Alfonso J. Cruz-Jentoft ${ }^{13}\left({ }^{10} \cdot\right.$ Andreas E. Stuck $^{14}(\mathbb{C}$
}

Received: 13 September 2021 / Accepted: 20 November 2021 / Published online: 1 January 2022

(c) The Author(s) 2021

\section{Key summary points}

Aim This scoping review aims to summarise recent developments in Geriatric Medicine that will potentially inform the updating of undergraduate medical curricula for geriatric content.

Findings Based on the thematic analysis of 367 records out of 2503 identified records, we summarised findings across six major themes: curriculum; topics; teaching methods; teaching settings; medical students' skills and medical students' attitudes.

Message This review could inform future shaping of undergraduate medical curricula for geriatric content, through model curricula, expansion of geriatric topics and use of various teaching methods and settings.

\begin{abstract}
Purpose The world's population is ageing. Therefore, every doctor should receive geriatric medicine training during their undergraduate education. This review aims to summarise recent developments in geriatric medicine that will potentially inform developments and updating of undergraduate medical curricula for geriatric content.

Methods We systematically searched the electronic databases Ovid Medline, Ovid Embase and Pubmed, from 1st January 2009 to 18th May 2021. We included studies related to (1) undergraduate medical students and (2) geriatric medicine or ageing or older adults and (3) curriculum or curriculum topics or learning objectives or competencies or teaching methods or students' attitudes and (4) published in a scientific journal. No language restrictions were applied.

Results We identified 2503 records and assessed the full texts of 393 records for eligibility with 367 records included in the thematic analysis. Six major themes emerged: curriculum, topics, teaching methods, teaching settings, medical students' skills and medical students' attitudes. New curricula focussed on minimum Geriatrics Competencies, Geriatric Psychiatry and Comprehensive Geriatric Assessment; vertical integration of Geriatric Medicine into the curriculum has been advocated. Emerging or evolving topics included delirium, pharmacotherapeutics, healthy ageing and health promotion, and Telemedicine. Teaching methods emphasised interprofessional education, senior mentor programmes and intergenerational contact, student journaling and reflective writing, simulation, clinical placements and e-learning. Nursing homes featured among new teaching settings. Communication skills, empathy and professionalism were highlighted as essential skills for interacting with older adults.

Conclusion We recommend that future undergraduate medical curricula in Geriatric Medicine should take into account recent developments described in this paper. In addition to including newly emerged topics and advances in existing topics, different teaching settings and methods should also be considered. Employing vertical integration throughout the undergraduate course can usefully supplement learning achieved in a dedicated Geriatric Medicine undergraduate course. Interprofessional education can improve understanding of the roles of other professionals and improve team-working skills. A focus on improving
\end{abstract}

Tahir Masud and Giulia Ogliari contributed equally to this work and are joint first co-authors.

Extended author information available on the last page of the article 
communication skills and empathy should particularly enable better interaction with older patients. Embedding expected levels of Geriatric competencies should ensure that medical students have acquired the skills necessary to effectively treat older patients.

Keywords Geriatric medicine $\cdot$ Geriatric psychiatry $\cdot$ Undergraduate medical education $\cdot$ Curriculum $\cdot$ Teaching methods

\section{Introduction}

Most doctors will encounter older adults in their practice, but the majority of older adults will not encounter a geriatrician [1]. Worldwide, the number of trained geriatricians per capita varies widely [2] and in many countries the specialty of Geriatric Medicine is still in its infancy [1, $3,4]$. Due to the population ageing and the medical complexity of older adults, every doctor should receive basic Geriatric Medicine training during their undergraduate education, aimed at developing knowledge, skills and attitudes relevant to older people [1]. Even where the teaching of Geriatric Medicine exists, there is considerable variation in its content and delivery across countries $[1,3,4]$. Harmonisation of undergraduate medical curricula across countries may facilitate the implementation of evidencebased practice and the international mobility of doctors.

In 2009, a European Summit on Age-Related Disease made strong recommendations on introducing geriatric content in the teaching of all healthcare professionals [3]. In 2014, the European undergraduate curriculum in Geriatric Medicine was developed through a Delphi process facilitated by the European Union of Medical SpecialistsGeriatric Medicine Section (UEMS-GMS) [5]. In preparation for this, a literature review of existing curricula was undertaken [6]. The final curriculum was published as a list of overarching learning outcomes and corresponding specific learning objectives; educational material was published to support its implementation [7]. Since then, there have been further developments in clinical practice, research and teaching in Geriatric Medicine. Accordingly, the UEMS-GMS board and the Education Specialist Interest Group (SIG) of the European Geriatric Medicine Society (EuGMS) have recommended that the curriculum is updated. Moreover, it was felt that the new curriculum should incorporate content on different teaching methods that can be employed to teach Geriatric Medicine to undergraduates, as this was lacking in the previous version of the curriculum.

The aim of this scoping review was to summarise recent developments in undergraduate Geriatric Medicine to inform the next iteration of the European undergraduate medical curriculum in Geriatric Medicine. The specific objectives were to review: (1) any recent Geriatric Medicine undergraduate curricula; (2) new curricular topics or new developments in existing topics; (3) teaching methods and teaching settings in Geriatric Medicine; (4) medical students' skills and attitudes in relation to Geriatric Medicine.

\section{Methods}

\section{Search strategies}

On 18th May 2021, we systematically searched the electronic databases Ovid Medline, Ovid Embase and Pubmed, using search algorithms developed with a clinical librarian as detailed in Supplementary Tables 1, 2 and 3. Our search terms combined three domains: (1) undergraduate medical students (or equivalent terms) AND (2) Geriatric Medicine or Ageing or Older People or Gerontology (or equivalent terms) AND (3) Curriculum or Education or Learning or Training or Teaching or Competencies or Objectives (or equivalent terms).

All records published online from 1st January 2009 to 18th May 2021 were included-2009 was the publication year of the previously mentioned literature review [6]. No language restrictions were applied and a translator was involved where necessary.

Through the UEMS-GMS network, we contacted experts in Geriatric Medicine, in Europe, Canada and Australia, to enquire about the existence of a national medical undergraduate curriculum in their countries.

\section{Selection criteria}

Studies that met the following criteria were included: (1) related to undergraduate medical students; (2) related to Geriatric Medicine or ageing or older adults; (3) related to curriculum or curriculum topics or learning objectives or competencies or teaching methods or teaching settings or students' attitudes towards older adults or Geriatric Medicine and (4) published in a scientific journal. We included studies on both medical and other healthcare students if they met the other criteria.

We excluded studies that: (1) did not specifically relate to undergraduate medical students but to other healthcare students; (2) did not specifically relate to Geriatric Medicine or ageing or older adults; (3) were related only 
to postgraduate medical education. We excluded these types of publication: (1) conference abstracts; (2) $\mathrm{PhD}$ theses and (3) medical students' dissertations. We further excluded duplicates and translations of pre-existing curricula.

\section{Study selection}

Three researchers (GO, EL, TM) independently screened titles and abstracts. Each record was screened for inclusion, based on title or abstract, by a pair of researchers working independently (GO and EL, GO and TM, TM and EL). Any disagreement was resolved through discussion between the two researchers or, if disagreement still persisted, through involvement of the third researcher.

\section{Data extraction and synthesis: theme-coding}

Four researchers (GO, EL, TM, AB) coded each record, by identifying and generating themes or subthemes in it, based on the full-text. Over 42 themes emerged and were grouped into six major themes. Due to the heterogeneity and large numbers of papers, we presented our findings in a narrative way, by identifying themes and selecting a few papers per theme. We preferentially selected papers that proposed model curricula or novel curricular topics, or which were systematic reviews of teaching methods or surveys.

\section{Results}

A total of 2503 records were identified from the electronic databases. After the removal of duplicates, conference abstracts and nursing or paediatric titles by the librarian, 1136 records remained. Following the screening of titles and/or abstracts, we excluded 743 records for the reasons shown in Fig. 1. The full texts of the remaining 393 records were assessed for eligibility and further 26 records were excluded. Finally, 367 records were included in the thematic analysis (Supplementary Excel file). Figure 1 details the search and study selection.

Of the 367 records, most were in English ( $n=350$ ), five in Spanish, four in Dutch, three in German, three in Japanese, one in French and one in Turkish. Records from high and low-middle income countries-and from all continentswere included.

Experts of the UEMS-GMS confirmed that a few countries have national recommendations on undergraduate medical education (e.g. France, UK, Germany, Switzerland and the Netherlands).

We identified six major themes in our papers: curricula; curricular topics; teaching methods; teaching settings; medical students' skills; medical students' attitudes (Table 1). Figure 2 illustrates the subthemes.

\section{Curricula}

Leipzig et al. developed a set of 26 Minimum Geriatrics Competencies for all graduating medical students - endorsed by the Association of American Medical Colleges (AAMC) [8]. These competencies were developed through a consensus process that involved almost half of U.S. medical schools, major medical education organisations and clinicians from several medical specialties. These competencies were nested within eight content domains: medication management; self-care capacity; falls, balance and gait disorders; hospital care; cognitive and behavioural disorders; atypical presentation of disease; health care planning and promotion; and palliative care.

Lehmann et al. built on the basic framework of the AAMC Minimum Geriatrics Competencies, by developing specific learning objectives for medical students in six geriatric mental health domains: normal ageing, mental health assessment, psychopharmacology, delirium, dementia and depression [9]. They advised vertical integration of these learning objectives in the curriculum across all years of medical school. More specifically, normal ageing and patient assessment could be covered during introductory and communication skills courses. Delirium and dementia could be included not only in geriatric or psychiatric clerkships but also in internal medicine, neurology and surgery clerkships; in this way, students would be reminded that they can encounter older adults with dementia or delirium in all clinical settings.

The Japanese core curriculum $[10,11]$ included a very detailed and comprehensive list of topics and competencies similar to that of Leipzig [8]. It included Comprehensive Geriatric Assessment (CGA) - a multidimensional holistic assessment of older adults-among the competencies required by newly qualified doctors; it emphasised health promotion through nutrition and falls prevention, and acknowledged the practice of the traditional Kampo medicine [11].

\section{Vertical integration of Geriatric Medicine into the curriculum}

Geriatric Medicine can be introduced to medical students during multiple pre-clinical and clinical courses, rather than confining it to a single Geriatric Medicine course. In this way, teaching can be reinforced through repeated exposure and core principles in the care of older people will be integrated into a wider learning. The Alpert Medical School of Brown University successfully integrated learning outcomes related to Geriatric Medicine into every course and every 


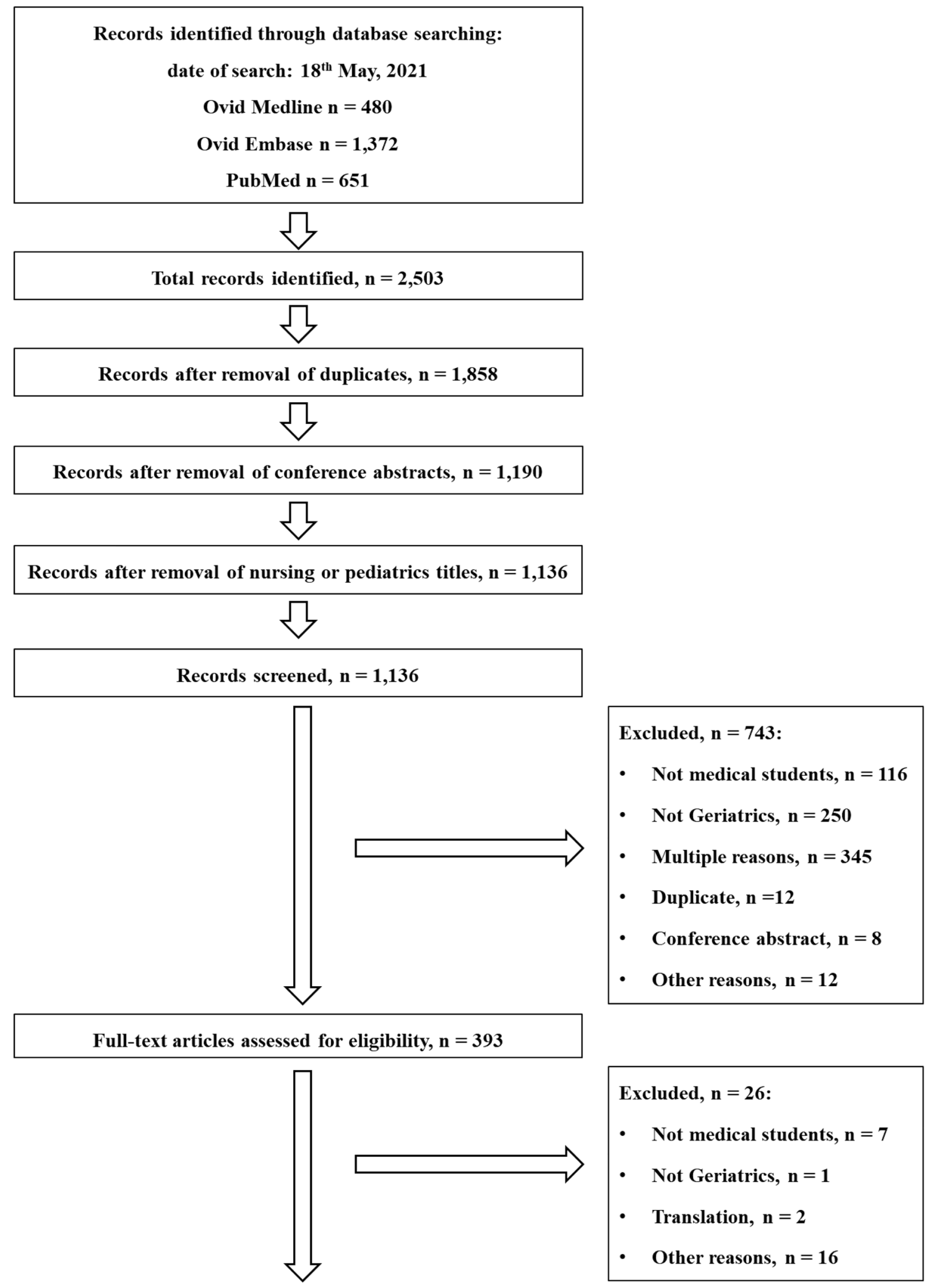

Studies included in the review, $\mathrm{n}=367$

Fig. 1 Flow-chart of studies selection 
Table 1 Classification of papers into categories of themes and subthemes

\begin{tabular}{|c|c|c|}
\hline Themes & Subthemes & Table \\
\hline Curriculum & $\begin{array}{l}\text { Model, design } \\
\text { Implementation } \\
\text { General considerations } \\
\text { Surveys }\end{array}$ & Supplementary Table 4 \\
\hline Topics & $\begin{array}{l}\text { Caregivers } \\
\text { Delirium, depression and dementia } \\
\text { Elder abuse } \\
\text { Falls and frailty } \\
\text { Geriatric psychiatry } \\
\text { Healthy ageing and health promotion } \\
\text { Pain } \\
\text { Palliative care } \\
\text { Pharmacy } \\
\text { Telemedicine } \\
\text { Transitions in care } \\
\text { Other topics }\end{array}$ & Supplementary Table 5 \\
\hline Teaching methods & $\begin{array}{l}\text { Active learning } \\
\text { Ageing game and serious games } \\
\text { Case-based learning } \\
\text { Contact with real patients } \\
\text { Creative arts } \\
\text { E-learning } \\
\text { Elective courses and workshops } \\
\text { Experiential learning } \\
\text { Flipped classroom } \\
\text { Geriatric block } \\
\text { Hidden curriculum } \\
\text { Intergenerational contact } \\
\text { Interprofessional education } \\
\text { Reflective learning / journaling } \\
\text { Research } \\
\text { Senior mentor programmes } \\
\text { Service learning } \\
\text { Simulation and standardised patients } \\
\text { Other or multiple teaching methods }\end{array}$ & Supplementary Table 6 \\
\hline Teaching settings & $\begin{array}{l}\text { Clerkship } \\
\text { Community } \\
\text { Long-term care settings } \\
\text { Home visits } \\
\text { Hospice } \\
\text { Rehabilitation }\end{array}$ & Supplementary Table 7 \\
\hline Skills & $\begin{array}{l}\text { Communication } \\
\text { Empathy } \\
\text { Leadership, moral distress and burnout, profes- } \\
\text { sionalism }\end{array}$ & Supplementary Table 8 \\
\hline Attitudes & $\begin{array}{l}\text { Towards ageing, dementia and frailty } \\
\text { Towards Geriatrics } \\
\text { Towards older adults }\end{array}$ & Supplementary Table 9 \\
\hline
\end{tabular}

year for every student as part of a comprehensive curriculum redesign [12]. Principles of Geriatric Medicine were successfully incorporated into anatomy classes [13]. The Geriatrics Anatomy programme consisted of a lecture on the pathophysiology of ageing and leading causes of death and an accompanying workshop in the anatomy laboratory [13]. In the workshop, a geriatrician stimulated students to recognise common anatomical findings associated with normal ageing or disease in the anatomy cadavers of older adults (i.e. left ventricular thickening, shrinkage of the kidneys). The students positively evaluated this programme, which helped them to understand the interplay of ageing and disease.

Many surveys on Geriatric Medicine in undergraduate medical education have been published worldwide [14-17]. In 2014, a systematic review showed that the learning outcomes, academic structures and qualified teachers to support effective undergraduate teaching in Geriatric Medicine 
Fig. 2 Word cloud of subthemes. This word cloud was powered by WordArt.com

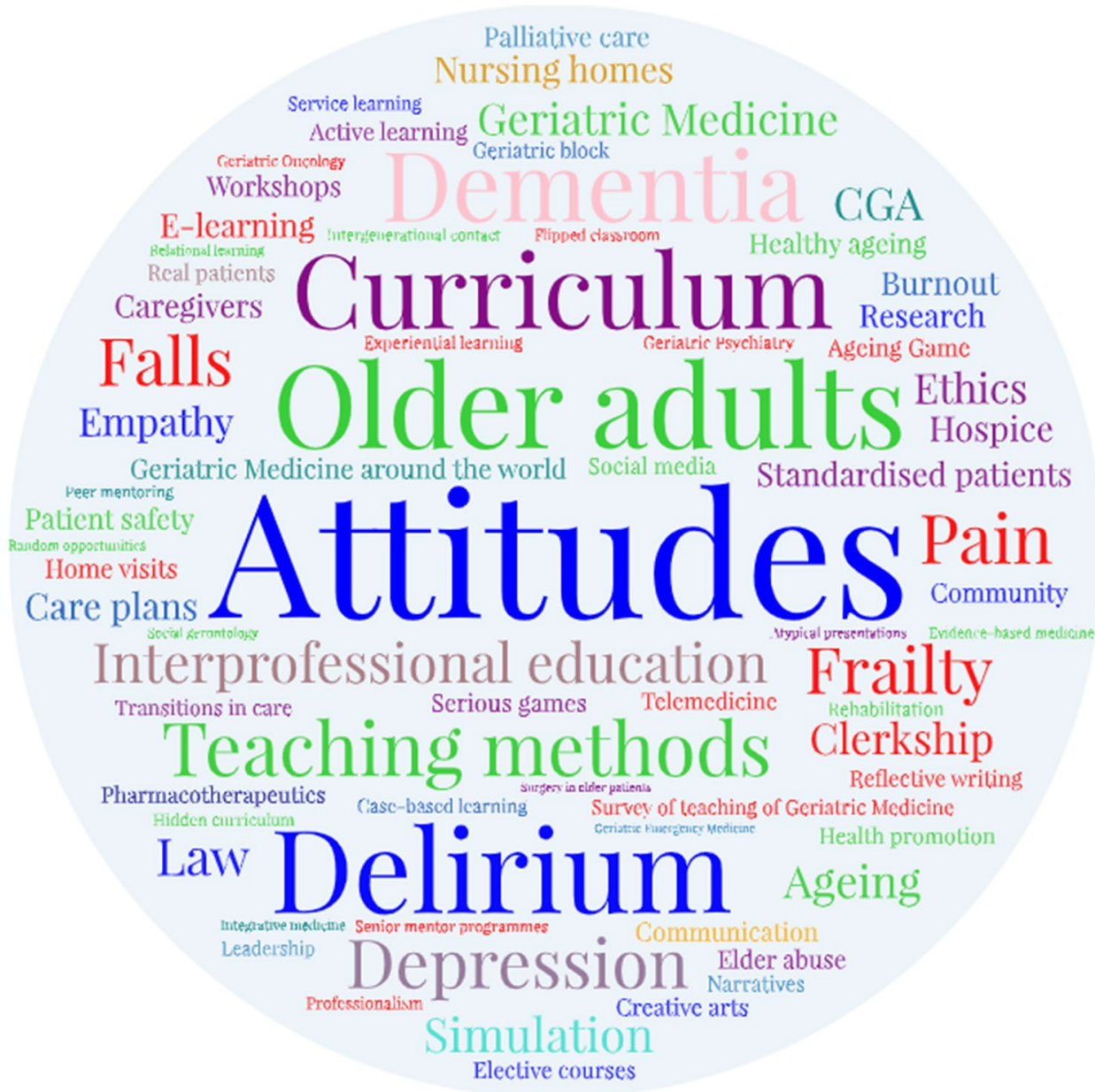

were not systematically available in most countries [14]. In Africa, a large number of medical institutions and countries did not teach Geriatric Medicine [15, 16]. In Latin America, the picture was very heterogeneous; Geriatric Medicine was taught in most undergraduate medical institutions in a few countries, while not being taught at all in other countries [17].

\section{Curricular topics}

\section{Delirium}

Copeland et al. developed a curriculum for delirium for undergraduate medical students [18]. They detailed curricular content as well as teaching methods and settings [18]. In particular, they advised that delirium should be taught both in acute settings such as emergency departments and hospital wards, and in long-term care home settings [18].

\section{Pharmacotherapeutics}

Liau et al. presented educational principles related to medication management in frail older people [19]. They advocated education on frailty and "the assessment, documentation and consideration of frailty at the time that medications are prescribed, dispensed and administered". They recommended education to minimise "low-value care", i.e. care that provides little or no benefit to patients, has potential to cause harm, leads to unnecessary cost or unnecessary use of limited resources. In relation to medications, lowvalue care includes continuation of potentially futile medications associated with adverse drug events. To minimise it, they recommended appropriate deprescribing, aided by the Screening Tool of Older Persons Prescriptions in Frail adults with limited life expectancy (STOPPFrail) and Beers criteria [19]. The recent International Union of Basic and Clinical Pharmacology (IUPHAR) curriculum also included "Polypharmacy and deprescribing" among the learning topics for medical students, stating that medical students should "identify medicines to deprescribe and apply deprescribing processes in older patients" [20]. 


\section{Healthy ageing and health promotion}

Key interventions to promote healthy ageing include exercise prescription, management of cardiovascular risk factors and vaccination in later life. Courses on exercise prescription in older adults have been introduced in undergraduate medical education in Australia [21]. Tersmette et al. highlighted that the management of hypertension, dyslipidaemia and overweight in older adults should have different targets compared to those for younger and middle-aged adults (e.g. higher blood pressure and cholesterol targets and being mildly overweight, though not obese, may be acceptable in later life); they recommended to introduce this concept into medical curricula [22]. Education on vaccination in older age has been undertaken in France [23].

\section{Frailty}

According to a survey, frailty was taught in most UK medical schools, generally during geriatric ward rounds [24]. The main topics were frailty definition and diagnosis, frailty screening and assessment tools, and less frequently frailty prevention [24]. Two medical schools taught frailty through interprofessional educational workshops on prescribing [24].

Malnutrition in older adults has a multifactorial aetiology, is highly prevalent and associated with reduced quality of life and an increased mortality risk; yet, it can be prevented and treated through nutritional therapy [25]. In most European countries, doctors are responsible for prescribing nutritional therapy and referring older adults to dieticians [25]. Yet, only a few European medical schools include nutrition in later life in undergraduate medical curricula [25]. Teaching on causes, assessment and consequences of malnutrition has been more frequently reported than that of perioperative nutrition or nutrition in intensive care units [25].

\section{Elder abuse}

Kapp advocated that medical education should include legal competencies, i.e. knowledge of the law, the legal system and knowledge on how to interact with it. In particular, medical students should be aware of legal and ethical considerations relating to confidentiality, shared-decision making, surrogate authority limits and the rights of "unbefriended" patients with no one to act or advocate on their behalf [26]. These are particularly necessary when dealing with elder abuse [26]. Partnerships between academic institutions and Social Services may promote teaching of elder abuse [27].

\section{Social gerontology}

Tinker et al. made a call for the universal teaching on Social Gerontology in UK medical schools, asserting that this may translate to a higher quality of care for older people, as medical students become more person-centred and empathetic in approach [28]. In particular, they advocated teaching on demography, sociology of ageing, psychology of ageing and social policy. They recommended that medical students should appreciate that ageing is highly heterogeneous and influenced by economic and socio-political factors [28]. Moreover, the psychology of ageing should focus not only on diseases such as dementia but also on resilience, coping strategies and health-seeking behaviours in older age [28]. Similarly, Lehmann et al. emphasised the concepts of heterogeneity of ageing, resilience with ageing and cohort effects (i.e. those "related to the events / values / experiences of the time period during which the older patient matured") [9]. Furthermore, Tersmette et al. highlighted the disability paradox (i.e. older adults may report well-being and social functioning despite physical and psycho-cognitive decline) [22].

\section{Telemedicine}

Telemedicine is a novel method of care delivery, progressively expanding across many medical specialties, in many countries. It was included in the French national curriculum $[29,30]$. A compulsory module on Telemedicine was successfully implemented at the University of Zurich and shown to improve medical students' confidence, knowledge and basic skills in Telemedicine [31]. In their feedback, most students wrote that they would like to provide telemedicine to care for chronic and older patients in their homes [31]. A French national survey showed that most medical students and residents acknowledged the relevance of Telemedicine for improving access to care but felt they were not sufficiently trained in its use [30].

\section{Teaching methods}

Interprofessional education is a collaborative educational approach whereby students of two or more health or social care professions learn interactively together with the aim of providing high-quality, patient-centred care [32]. Advantages of interprofessional education for students are: understanding role delineation; expanding knowledge; learning group dynamics; feeling supported by the team; enhancing group learning; understanding other disciplines; communicating as a team [32]. Interprofessional education can take place in various settings, including residential homes, nursing homes and senior housing residences [32, 33]. For example, the Interprofessional Geriatrics Curriculum was designed to train medical students and other healthcare students to work as a team in the care of older adults in a community-based senior housing unit [33]. Collectively, by the end of it, students of all professions demonstrated a 
higher likelihood of understanding their roles in an interprofessional healthcare team than before it [33]. While most interprofessional learning activities emphasise knowledge and definition of roles, a few explore fluidity of roles [34].

Senior mentor programmes aim to promote medical students' deeper understanding of ageing and age-associated conditions, by pairing medical students with older adults (the "mentors"). The mentors could be healthy, independent community-dwelling older adults or older adults with early dementia [35-38]. Programmes involving mentors, who represent various aspects of successful ageing, aim to broaden medical students' concept of ageing to include healthy ageing. In the Partnering in Alzheimer's Instruction Research Study (PAIRS) Program, medical students were paired with an adult with early-stage Alzheimer's disease for 1 year [35]. Participation in this programme led to a modest improvement in medical students' dementia knowledge, as shown by preand post-programme tests [35]. Moreover, qualitative analyses of post-programme students' reflective essays showed that students had gained more humanistic insights into dementia, had more positive attitudes towards Geriatric Medicine and felt more comfortable with their communication skills [35]. While the PAIRS Program and many others were an elective part of the curriculum, The Time for Dementia Programme was a core element of the undergraduate medical curriculum at a UK medical school [36]. It provided all medical students with a longitudinal experience of how individuals and their families are affected by dementia, to improve students' attitudes, compassion, empathy and knowledge of dementia [36]. In this programme, medical students visited a person with dementia and their family in pairs for $2 \mathrm{~h}$ every 3 months for 2 years [36].

Besides the senior mentor programmes, other programmes were reported which foster intergenerational contact, to support students' understanding of ageing. For example, the Newcastle University Ageing Generations Education brought together students and older adults to discuss the subject of ageing in an educational context [39]. Following participation in this programme, students reported increased confidence communicating with older people and a better understanding of the diversity of the ageing experience [39].

Simulation games sensitise medical students to the challenges of older age. In the Ageing Game, students first envision themselves as ageing and older, then they are assigned various physical disabilities and play various roles to experience the world from the perspective of older adults. Finally, they have a group discussion about this [40]. The Ageing Game has been shown to improve medical students' empathy towards older adults but to worsen attitudes [40].

Serious games have been used for the purposes of medical education for decades. The game GeriatriX was assessed in a controlled study at a Dutch university [41]. In GeriatriX, medical students decided which investigations and treatments to order for three older patients, all with anaemia but with different treatment preferences and levels of frailty [41]. Therefore, each patient's optimal diagnostic and therapeutic strategy differed [41]. Students received digital feedback on their choices, based on patients' preferences, clinical reasoning and healthcare cost [41]. After playing GeriatriX, students felt more competent in weighing patient preferences, appropriateness, and costs of medical care in complex geriatric medical decision making [41]. GeriatriX was also enjoyable and improved medical students' attitudes toward Geriatrics [41]. Recently, serious games to teach delirium to medical students have been developed and tested in controlled-trials [42-44]. The serious game Delirium Experience had a positive effect on students' skills in advising care for delirious patients, learning motivation and engagement and self-reported knowledge on delirium, while not affecting students' attitude towards patients with delirium [44].

Student journaling — reflective or narrative writing —on teaching and clinical experiences can foster student selfreflection but also be used to assess "real-time" student attitudes and responses to curriculum redesign [12]. As an example, the Medical School of an American University integrated geriatrics into every course, every year, for every student as part of a comprehensive curriculum redesign [12]. Pre-clinical and clerkship students wrote narratives, each week or every other week, in response to standard questions on the geriatric content in medical courses, and on the older adults encountered in the various settings and during clinical experiences [12]. The narratives were analysed by a multidisciplinary team according to qualitative methods; they provided real-time feedback to course directors and allowed midcourse modifications [12]. Interestingly, a student asked to be exposed to normal ageing [12].

Simulation has been used to teach various topics, including delirium [45], elder abuse [46], frailty, falls and osteoporosis [47]. It has also been used to practice various skills, including communication with adults with dementia [48, 49], interprofessional team working [50], medication management [51-53], end-of-life care discussions [54], CGA [55], basic oral and dental care in older adults [56], and management of depression in older adults [57].

Clinical placements or clerkships are a traditional teaching and training method for medical students. Geriatric clerkships can take place in acute care hospital wards and more frequently in outpatient settings, rehabilitation units, residential and nursing homes. Geriatric clerkships can fulfil a medical school's internal medicine rotation requirement. A study found that examination proficiency was similar, while greater confidence in treating older adults and more positive attitudes towards older adults were found in the students completing a geriatric versus an internal medicine clerkship [58]. 
E-learning. A notable example of an e-learning course is Aquifer Geriatrics [59]. It consists of 26 evidence-based, peer-reviewed, yearly-updated, online case-based modules, based on the Minimum Geriatrics Competencies by Leipzig et al. [8]. The cases explore multifactorial aetiologies and multidimensional treatments. Role modelling conversations are used to teach communication skills; additional information is provided for further learning. In response to the COVID-19 pandemic many institutions restricted the availability of clinical rotation sites and deployed e-learning and distant learning to compensate for this [60, 61].

The flipped classroom refers to an educational model in which the teachers reverse, or "flip," their classes so that lectures traditionally given during class are watched by students outside of class, while homework traditionally completed outside of class is completed in class [62, 63]. Specifically, students read literature and watch online lecture material prior to class, while they dedicate class time to complete activities that help deepen understanding of the lecture or apply lecture content to problem-solving. In the flipped classroom, it is the student rather than the teacher who is active during class time. The flipped classroom with online lecture material has several advantages. In particular, students may: (1) control the pace of lectures, based on their comprehension and ability levels (i.e., by re-watching lecture material that they may not fully understand while speeding through materials that they do understand); (2) re-watch lectures in preparation for exams or for personal interest and (3) not miss lectures due to illness, travel or lockdown.

Service learning is a form of experiential learning, in which students learn through tackling real-life problems in their community. Service learning can take place in various settings, including nursing homes, hospices, assisted living facilities and day centres [64-66]. In an elective servicelearning course, medical students conducted needs assessments in diverse older adult communities, created health education projects and reflected on their experiences through written assignments and presentations [64]. During an artsfocussed, service-learning course, undergraduate students learnt to connect with adults with dementia in a meaningful way by interviewing them on their favourite songs and uploading them on iPods [65]. Opportunities for servicelearning in nursing homes have been described also during the COVID-19 pandemic, in compliance with safety measures [66]; by restoring a sense of community, they have been mutually beneficial for both volunteer medical students and older residents in nursing homes [66].

Short-term research training programmes focussed on ageing have been shown to improve medical students' attitudes toward ageing and older adults and promote interest in Geriatrics as a career [67]. In many American Universities, scholarly concentration programmes provide undergraduate medical students with opportunities for scholarship in their chosen areas of interest, beyond their traditional core curricula. These programmes allow students in-depth study, faculty mentorship and a scholarly product such as a paper or presentation. A few of these programmes have focussed on Geriatric Medicine and have been characterised by high students' satisfaction [68].

Creative arts-literature, music, visual and other artsmay be used to foster communication between medical students and older adults (particularly those with dementia) [65] or to enhance students' reflection on their thoughts and emotions sparked by their encounters with older adults [69]. In an educational intervention integrated into a mandatory clerkship, all students at Weill Medical College, Cornell University, made home visits to homebound older adults with an interdisciplinary team. Then, students channelled their thoughts and emotions elicited by the home visits into creative art projects, which were presented and discussed in interdisciplinary group discussion [69]. This group discussion allowed students to gain insight into their peers' experiences and associated thoughts, emotions and reflections, thus promoting self-reflection and self-development [69].

\section{Teaching settings}

Nursing homes are emerging as a relevant teaching setting for Geriatric Medicine [70]. Nursing homes are ideal sites for bedside teaching, interprofessional education, communication with families and education on patient safety, quality improvement projects and transitions in care (for example, between acute care hospitals and nursing homes) [70]. Copeland et al. advised that delirium teaching also should occur in long-term care homes [18]. Home visits allow medical students to see older adults in their own environment, thus illustrating the interplay of psychosocial and medical factors [69]. Moreover, student attitudes towards older patients may be improved by experiences that are based in the community rather than a hospital environment [69].

\section{Skills}

Many papers focussed on communication skills, empathy and professionalism (Supplementary Table 5). Several papers focussed on communication with adults with dementia [48, 49, 65] or delirium [71] or with an end-oflife condition [72]. Liau et al. emphasised communication between care providers, patients and their caregivers in relation to medication management [19]. The development of empathy could improve medical students' attitudes towards older adults. Visiting older adults in a nursing home fostered empathy and a more holistic approach towards older adults among medical students [73]. Medical students may experience moral distress and burnout when caring for older adults $[74,75]$. 


\section{Attitudes}

Several papers explored medical students' attitudes (a) towards ageing and age-related conditions such as dementia and frailty, (b) towards older adults and (c) towards Geriatric Medicine as a career choice (Supplementary Table 4). Negative attitudes of medical students towards older adults and a low interest in Geriatrics as a career were frequently reported, with only $3-4 \%$ of students having a strong interest in Geriatrics $[67,76]$. A lack of interest may be partly due to a lack of exposure to Geriatric Medicine during undergraduate education, low financial rewards and low status associated with Geriatric Medicine careers in a few countries [76]. Clerkships in Geriatric Medicine favour students' exposure to it but it is unclear whether this results in sustained increased interest in the specialty or care of older people more generally [76]. Of note, attitudes on caring for older adults rather than more general attitudes towards older adults may better predict the choice of Geriatric Medicine as a career [77]. A medical students' focus group highlighted perceived barriers to Geriatric Medicine as a career choice, including common ethical dilemmas, difficult communication with older patients, time-consuming assessment of older patients and what were perceived as being unrealistic expectations of patients and family members [77]. In Canada, medical students reported that the length of postgraduate training (five years) in Geriatric Medicine was a barrier to choose it as a career [76].

\section{Discussion}

Our systematic literature search retrieved a large number of published papers on undergraduate medical education in Geriatric Medicine around the world, in the last thirteen years. We identified six major themes: curriculum; curricular topics; teaching methods; teaching settings; medical students' skills; and medical students' attitudes. We chose a narrative synthesis of our findings through selected papers on the main themes, due to the large number of papers, the heterogeneity of topics and the inclusion of qualitative and mixed-methods research papers, which did not allow us to perform a meta-analysis.

Model curricula, which were developed through a consensus process, set learning objectives and competencies for undergraduate medical students in Geriatric Medicine, Geriatric Psychiatry or specific topics $[8,9,18]$.

Our review documented an expanding teaching on topics such as delirium, pharmacotherapeutics and deprescribing, healthy ageing and health promotion, elder abuse and legal competencies, and telemedicine. We recommend that undergraduate curricula that do not include these topics should be extended to incorporate them or adjusted to reflect the evolving knowledge on these.
In particular, medication management has already been included in many undergraduate curricula, including Leipzig et al. [8] and British Geriatric Society [78]. Recently, deprescribing has gained increasing attention. It is motivated by lack of evidence on the safety and effectiveness of drugs in older adults-remarkably underrepresented in clinical trials-and by considerations on frailty $[19,20]$. Lehmann et al. stated that medical students must identify the medications that may cause or worsen cognitive impairment in older adults [9]. Liau et al. recommended education on frailty assessment in relation to medication management, especially assessing the patient's capacity to self-manage medications, using standardised assessment tools [19]. They also recommended education to minimise low-value care, by deprescribing unnecessary or inappropriate medications and regularly reviewing medication regimens to align with changing goals of care [19]. Furthermore they specified that deprescribing should consider therapeutic intents, time to benefit, optimal dosing, adverse drug effects, risks and benefits and patient preferences [19].

Clinicians and medical students have reported limited selfefficacy in deprescribing [79], warranting further education on deprescribing and deprescribing tools. These include The American Geriatrics Society Choosing Wisely Workgroup's publications, the updated Beers Criteria ${ }^{\circledR}$, the FORTA (Fit fOR The Aged) List, the Screening Tool of Older People's Prescriptions and Screening Tool to Alert to Right Treatment (STOPP/START) criteria, and the Screening Tool of Older Persons Prescriptions in older adults with high fall risk (STOPPFall) [80-85]. In our view, the learning outcomes of medical students should include knowledge of deprescribing tools and of age- and frailty-related changing risk management and treatment goals. On the other hand, we advocate prescription and optimization of medications of proven efficacy and benefit, which could be underprescribed in older adults [86].

Furthermore, we advocate the systematic and universal teaching on healthy ageing and health promotion in medical schools. We recommend that teaching on vaccinations for older adults is included in undergraduate Geriatric Medicine courses. Currently, vaccinations are generally taught to medical students during courses of Paediatrics and Public Health, but not during Internal or Geriatric Medicine courses [87]. As a result, older adults may not appear as a target population who would benefit from effective vaccinations, including those for influenza, pneumococcus and herpes zoster [87, 88] and, now, COVID-19. In 2020, COVID-19 was the third leading cause of death in the US behind heart disease and cancer, disproportionately affecting older and frailer adults [89].

Several Authors advocated [9] and implemented [12] a vertical integration of Geriatric Medicine into the curricula. Given the overcrowded medical curricula, Geriatric Medicine may not only compete with other specialties for single 
teaching modules but also cooperate and deliver geriatric content within other specialties. This vertical integration has various motivations and advantages. First, a few topics naturally fall within and across multiple disciplines: late-life depression within Psychiatry; delirium and dementia within Internal Medicine, Neurology and Surgery; pharmacotherapeutics for older adults in Pharmacology. Second, this vertical integration would reflect the clinical reality: older adults are encountered in all clinical settings. Finally, repeated exposure to Geriatric Medicine may reinforce teaching, and exposure in a non-Geriatric Medicine setting may counteract medical students' negative attitudes towards older adults. On the negative side, vertical integration may "dilute" Geriatric Medicine, compared with other disciplines, and its teaching may rely on non-geriatricians. Yet, co-teaching by geriatricians and non-geriatricians could be implemented, thus fostering high-quality, multidisciplinary education.

Furthermore, we advocate an expansion of teaching settings, beyond acute care setting. Long-term care and community settings offer great opportunities for CGA and interprofessional education and may provide medical students with a holistic view of older adults $[69,70,73]$.

We have presented evidence in favour of a variety of teaching methods that promote learning of Geriatric Medicine. As an adjunct to traditional lectures, active and interactive learning approaches have been described. Clinical clerkships remain a cornerstone of teaching, now taking place in Geriatric Medicine acute wards, long-term care and community settings. Direct comparisons of the efficacy and effectiveness of teaching methods and settings are few [58]. Thus, we cannot recommend any one method above the others. Adopting a variety of teaching methods could maximise impact on students with different learning styles and preferences. Clinical clerkships and senior mentor programmes favour medical students' contact with real people; simulation may ensure systematic exposure to clinical cases, rather than being determined by the older adults medical students happen to come into contact with. Moreover, the selection of teaching methods should take into account the resources available to each medical institution and the cultural context. Senior mentor programmes may not be needed in countries where intergenerational families are prevalent. We recommend a systematic curriculum redesign so that every student is exposed to Geriatric Medicine. Besides this, elective courses and workshops may be developed for students with special interest towards Geriatric Medicine.

Major strengths of our paper are the high relevance of the topic and the systematic literature search. Our comprehensive search of three electronic databases, with the support of a clinical librarian, retrieved a large number of published papers from countries across the world. No language restrictions were applied and papers in seven languages from many countries were included. We involved international experts so as not to miss other relevant published papers. Moreover, the eligible studies were selected through consensus of two or three researchers and all selected studies were themecoded. A further strength is that we highlighted not only the contents of Geriatric Medicine that could be taught but also the variety of teaching methods used to deliver these contents and students' attitudes that may modulate learning. Copeland et al. chose a similar approach in the development of a curriculum on delirium [18], citing that a curriculum is "a planned educational experience that encompasses behavioural goals, instructional methods and actual experiences of the learners" [90].

Our paper has a few limitations. First, we included only papers published in peer-reviewed journals, thus excluding national recommendations on learning objectives that could be published on governmental websites or medical societies' websites [78, 91]. Second, we did not systematically carry out and present a quality appraisal of all papers; yet, we selected only papers published in peer-reviewed journals. Third, we did not systematically explore the impact of the COVID-19 pandemic on healthcare and education, though we mentioned changes in educational methods and settings in response to the pandemic $[60,61,66]$. The pandemic has favoured a shift towards Telemedicine and Telepsychiatry in clinical practice [92]; yet, few papers explored these as educational topics [29-31], without mentioning digital inequalities, which could particularly affect older adults, with cognitive or sensory impairments or simply lacking digital competencies or devices. Moreover, the pandemic has had multifold consequences on older adults, changing the prevalence and relative impact of various conditions or disease risk factors - such as loneliness, physical inactivity and barriers to access healthcare [93]. Thus, health promotion and education efforts may adjust their priorities and methods in view of the evolving pandemic.

In conclusion, efforts to promote undergraduate medical education in Geriatric Medicine have been undertaken worldwide. This review should inform future consensusled developments or revisions of undergraduate curricula in relation to Geriatric Medicine. Further research should explore the implementation of curricula and the impact of the COVID-19 pandemic on undergraduate medical education.

Supplementary Information The online version contains supplementary material available at https://doi.org/10.1007/s41999-021-00595-0.

Acknowledgements Evidence Search: Geriatrics curriculum (LS39). Lindsay Snell (2021). Derby, UK: University Hospitals of Derby \& Burton NHS Foundation Trust Library and Knowledge Service. We gratefully thank Ms Reika Nakai for interpreting the papers in Japanese language. We gratefully thank Ms Katie Robinson and Mr Lasse Lybecker Scheel-Hincke for support during the literature search. We gratefully thank the EuGMS SIG on Education and Training for valuable input and information on teaching in Geriatric Medicine across 
European countries. We presented and debated very preliminary findings of our review at the online SIG Collateral Meeting, 17th EuGMS Congress, Athens, 13th October 2021.

Author contributions TM, GO: study concept and design, literature search, drafting the manuscript. TM, GO, EL, AB: data extraction and synthesis. EL, AB, ALG, RRW, MV, DM, MK, KS, RRO, AJCJ, AS: study concept, critical revision of manuscript for intellectual content. All authors read and approved the final manuscript.

Funding Dr Giulia Ogliari was supported by grant APP2380/N7359 (OSTEOPOROSIS \& FALLS RESEARCH) by Nottingham Hospitals Charity.

Data availability Not applicable.

Code availability Not applicable.

\section{Declarations}

Conflict of interest On behalf of all authors, the corresponding author states that there is no conflict of interest.

Ethics approval Not applicable.

Consent to participate Not applicable.

Consent for publication Not applicable.

Open Access This article is licensed under a Creative Commons Attribution 4.0 International License, which permits use, sharing, adaptation, distribution and reproduction in any medium or format, as long as you give appropriate credit to the original author(s) and the source, provide a link to the Creative Commons licence, and indicate if changes were made. The images or other third party material in this article are included in the article's Creative Commons licence, unless indicated otherwise in a credit line to the material. If material is not included in the article's Creative Commons licence and your intended use is not permitted by statutory regulation or exceeds the permitted use, you will need to obtain permission directly from the copyright holder. To view a copy of this licence, visit http://creativecommons.org/licenses/by/4.0/.

\section{References}

1. Keller I, Makipaa A, Kalenscher T, Kalache A (2002) Global survey on geriatrics in the medical curriculum. World Health Organization, Geneva

2. Michel JP, Ecarnot F (2020) The shortage of skilled workers in Europe: its impact on geriatric medicine. Eur Geriatr Med 11(3):345-347. https://doi.org/10.1007/s41999-020-00323-0

3. Cruz-Jentoft AJ, Franco A, Sommer P et al (2009) Silver paper: the future of health promotion and preventive actions, basic research, and clinical aspects of age-related disease-a report of the European summit on age-related disease. Aging Clin Exp Res 21(6):376-385. https://doi.org/10.1007/BF03327452

4. Kotsani M, Ellul J, Bahat G et al (2020) Start low, go slow, but look far: the case of geriatric medicine in Balkan countries. Eur Geriatr Med 11(5):869-878. https://doi.org/10.1007/ s41999-020-00350-x

5. Masud T, Blundell A, Gordon AL et al (2014) European undergraduate curriculum in geriatric medicine developed using an international modified Delphi technique. Age Ageing 43(5):695702. https://doi.org/10.1093/ageing/afu019

6. Blundell A, Gordon A, Gladman J, Masud T (2009) Undergraduate teaching in geriatric medicine: the role of national curricula Gerontol Geriatr Educ 30(1):75-88. https://doi.org/10.1080/02701 960802690324

7. Learning Geriatric Medicine (2018) A study guide for medical students. Springer International Publishing, Germany

8. Leipzig RM, Granville L, Simpson D, Anderson MB, Sauvigné K, Soriano RP (2009) Keeping granny safe on July 1: a consensus on minimum geriatrics competencies for graduating medical students. Acad Med 84(5):604-610. https://doi.org/10.1097/ACM. 0b013e31819fab70

9. Lehmann SW, Brooks WB, Popeo D, Wilkins KM, Blazek MC (2017) Development of geriatric mental health learning objectives for medical students: a response to the institute of medicine 2012 report. Am J Geriatr Psychiatry 25(10):1041-1047. https://doi. org/10.1016/j.jagp.2017.05.006

10. Arai $\mathrm{H}$. [Model core curriculum and geriatrics education in medical school]. Nihon Ronen Igakkai Zasshi. 2010;47(4):285-287. Japanese. https://doi.org/10.3143/geriatrics.47.285

11. [Model core curriculum in undergraduate medical education and geriatric medicine] Nihon Ronen Igakkai Zasshi. 2019;56(1):1621. Japanese. https://doi.org/10.3143/geriatrics.56.16

12. Shield RR, Farrell TW, Nanda A, Campbell SE, Wetle T (2012) Integrating geriatrics into medical school: student journaling as an innovative strategy for evaluating curriculum. Gerontologist 52(1):98-110. https://doi.org/10.1093/geront/gnr079

13. McNicoll L, Fulton AT, Ritter D, Besdine RW (2012) Cadaver treasure hunt: introducing geriatrics concepts in the anatomy class. J Am Geriatr Soc 60(5):962-966. https://doi.org/10.1111/j. 1532-5415.2012.03951.x

14. Mateos-Nozal J, Cruz-Jentoft AJ, Ribera Casado JM (2014) A systematic review of surveys on undergraduate teaching of Geriatrics in medical schools in the XXI century. Eur Geriatr Med 5(2):119-124. https://doi.org/10.1016/j.eurger.2013.12.006

15. Dotchin CL, Akinyemi RO, Gray WK, Walker RW (2013) Geriatric medicine: services and training in Africa. Age Ageing 42(1):124-128. https://doi.org/10.1093/ageing/afs119

16. Frost L, Liddie Navarro A, Lynch M et al (2015) Care of the elderly: survey of teaching in an aging sub-Saharan Africa. Gerontol Geriatr Educ 36(1):14-29. https://doi.org/10.1080/02701960. 2014.925886

17. López JH, Reyes-Ortiz CA (2015) Geriatric education in undergraduate and graduate levels in Latin America. Gerontol Geriatr Educ 36(1):3-13. https://doi.org/10.1080/02701960.2014.911662

18. Copeland C, Fisher J, Teodorczuk A (2018) Development of an international undergraduate curriculum for delirium using a modified delphi process. Age Ageing 47(1):131-137. https://doi.org/ 10.1093/ageing/afx133

19. Liau SJ, Lalic S, Sluggett JK et al (2021) Medication management in frail older people: consensus principles for clinical practice, research, and education. J Am Med Dir Assoc 22(1):43-49. https://doi.org/10.1016/j.jamda.2020.05.004

20. Kashyap M, Thuermann P, Le Couteur DG, Abernethy DR, Hilmer SN (2019) IUPHAR international geriatric clinical pharmacology curriculum for medical students. Pharmacol Res 141:611-615. https://doi.org/10.1016/j.phrs.2019.01.032

21. Jadczak AD, Tam KL, Visvanathan R (2018) Educating medical students in counselling older adults about exercise: the impact of a physical activity module. J Frailty Aging 7(2):113-119. https:// doi.org/10.14283/jfa.2017.44

22. Tersmette W, van Bodegom D, van Heemst D, Stott D, Westendorp R (2013) Gerontology and geriatrics in Dutch medical education. Neth J Med 71(6):331-337 
23. Belmin J, Bourée P, Camus D et al (2009) Educational vaccine tools: the French initiative. Aging Clin Exp Res 21(3):250-253. https://doi.org/10.1007/BF03324906

24. Winter R, Al-Jawad M, Wright J et al (2021) What is meant by "frailty" in undergraduate medical education? A national survey of UK medical schools. Eur Geriatr Med 12(2):355-362. https:// doi.org/10.1007/s41999-021-00465-9

25. Eglseer D, Visser M, Volkert D et al (2019) Nutrition education on malnutrition in older adults in European medical schools: need for improvement? Eur Geriatr Med 10:313-318. https://doi.org/ 10.1007/s41999-018-0154-Z

26. Kapp MB (2018) Teaching legal competencies through an individualized elective in medicine and law. Gerontol Geriatr Educ 39(4):491-494. https://doi.org/10.1080/02701960.2016.1247072

27. Dyer CB, Halphen JM, Lee J et al (2020) Stemming the tide of elder mistreatment: a medical school-state agency collaborative. Acad Med 95(4):540-545. https://doi.org/10.1097/ACM.00000 00000003028

28. Tinker A, Hussain L, D'Cruz JL, Tai WY, Zaidman S (2016) Why should medical students study social gerontology? Age Ageing 45(2):190-193. https://doi.org/10.1093/ageing/afw003

29. Yaghobian S, Ohannessian R, Mathieu-Fritz A, Moulin T (2020) National survey of telemedicine education and training in medical schools in France. J Telemed Telecare 26(5):303-308. https://doi. org/10.1177/1357633X18820374

30. Yaghobian S, Ohannessian R, Iampetro T, et al. Knowledge, attitudes and practices of telemedicine education and training of French medical students and residents [published online ahead of print, 2020 Jun 9]. J Telemed Telecare. 2020;1357633X20926829. https://doi.org/10.1177/1357633X20 926829

31. Brockes C, Grischott T, Dutkiewicz M, Schmidt-Weitmann S (2017) Evaluation of the education "clinical telemedicine/ehealth" in the curriculum of medical students at the university of Zurich. Telemed J E Health 23(11):899-904. https://doi.org/10. 1089/tmj.2017.0011

32. Holmes SD, Smith E, Resnick B et al (2020) Students' perceptions of interprofessional education in geriatrics: a qualitative analysis. Gerontol Geriatr Educ 41(4):480-493. https://doi.org/10.1080/ 02701960.2018 .1500910

33. Reilly JM, Aranda MP, Segal-Gidan F et al (2014) Assessment of student interprofessional education (IPE) training for team-based geriatric home care: Does IPE training change students' knowledge and attitudes? Home Health Care Serv Q 33(4):177-193. https://doi.org/10.1080/01621424.2014.968502

34. Byerly LK, Floren LC, Yukawa M, O’Brien BC (2021) Getting outside the box: exploring role fluidity in interprofessional student groups through the lens of activity theory. Adv Health Sci Educ Theory Pract 26(1):253-275. https://doi.org/10.1007/ s10459-020-09983-w

35. Jefferson AL, Cantwell NG, Byerly LK, Morhardt D. Medical student education program in Alzheimer's disease: the PAIRS Program. BMC Med Educ. 2012;12:80. Published 2012 Aug 21. https://doi.org/10.1186/1472-6920-12-80

36. Banerjee S, Farina N, Daley S et al (2017) How do we enhance undergraduate healthcare education in dementia? A review of the role of innovative approaches and development of the time for Dementia programme. Int J Geriatr Psychiatry 32(1):68-75. https://doi.org/10.1002/gps.4602

37. Mendoza De La Garza M, Tieu C, Schroeder D, Lowe K, Tung E. Evaluation of the Impact of a senior mentor program on medical students' geriatric knowledge and attitudes toward older adults. Gerontol Geriatr Educ. 2018;39(3):316-325. https://doi.org/10. 1080/02701960.2018.1484736

38. Basran JF, Dal Bello-Haas V, Walker D et al (2012) The longitudinal elderly person shadowing program: outcomes from an interprofessional senior partner mentoring program. Gerontol Geriatr Educ 33(3):302-323. https://doi.org/10.1080/02701960. 2012.679369

39. Forster J, Tullo E, Wakeling L, Gilroy R (2021) Involving older people in inclusive educational research. J Aging Stud 56:100906. https://doi.org/10.1016/j.jaging.2020.100906

40. Lucchetti AL, Lucchetti G, de Oliveira IN, Moreira-Almeida A, da Silva Ezequiel O. Experiencing aging or demystifying myths? impact of different "geriatrics and gerontology" teaching strategies in first year medical students. BMC Med Educ. 2017;17(1):35. Published 2017 Feb 8. https://doi.org/10.1186/s12909-017-0872-9

41. van de Pol MH, Lagro J, Fluit LR, Lagro-Janssen TL, Olde Rikkert MG. Teaching geriatrics using an innovative, individual-centered educational game: students and educators win. A proof-ofconcept study. J Am Geriatr Soc. 2014;62(10):1943-1949. https:// doi.org/10.1111/jgs.13024

42. Buijs-Spanjers KR, Hegge HH, Cnossen F, Jaarsma DA, de Rooij SE. Reasons to Engage in and Learning Experiences From Different Play Strategies in a Web-Based Serious Game on Delirium for Medical Students: Mixed Methods Design. JMIR Serious Games. 2020;8(3):e18479. Published 2020 Jul 29. https://doi.org/10.2196/ 18479

43. Buijs-Spanjers KR, Harmsen A, Hegge HH, Spook JE, de Rooij $\mathrm{SE}$, Jaarsma DADC. The influence of a serious game's narrative on students' attitudes and learning experiences regarding delirium: an interview study. BMC Med Educ. 2020;20(1):289. Published 2020 Sep 1. https://doi.org/10.1186/s12909-020-02210-5

44. Buijs-Spanjers KR, Hegge HH, Jansen CJ, Hoogendoorn E, de Rooij SE. A Web-Based Serious Game on Delirium as an Educational Intervention for Medical Students: Randomized Controlled Trial. JMIR Serious Games. 2018;6(4):e17. Published 2018 Oct 26. https://doi.org/10.2196/games.9886

45. Robles MJ, Esperanza A, Pi-Figueras M, Riera M, R. Miralles R. Simulation of a clinical scenario with actresses in the classroom: A useful method of learning clinical delirium management. Eur Geriatr Med. 2017;8(5-6):474-479. https://doi.org/10.1016/j. eurger.2017.07.011

46. Fisher JM, Rudd MP, Walker RW, Stewart J (2016) Training tomorrow's doctors to safeguard the patients of today: using medical student simulation training to explore barriers to recognition of elder abuse. J Am Geriatr Soc 64(1):168-173. https://doi.org/ 10.1111 /jgs. 13875

47. Robles MJ, Esperanza A, Arnau-Barrés I, Garrigós MT, Miralles R (2019) Frailty, falls and osteoporosis: learning in elderly patients using a theatrical performance in the classroom. J Nutr Health Aging 23(9):870-875. https://doi.org/10.1007/s12603-019-1272-0

48. Winter R, Al-Jawad M, Harris R, Wright J (2020) Learning to communicate with people with dementia: exploring the impact of a simulation session for medical students (Innovative practice). Dementia (London) 19(8):2919-2927. https://doi.org/10.1177/ 1471301219845792

49. Cockbain BC, Thompson S, Salisbury H, Mitter P, Martos L (2015) A collaborative strategy to improve geriatric medical education. Age Ageing 44(6):1036-1039. https://doi.org/10.1093/ ageing/afv 100

50. Mcquown C, Ahmed RA, Hughes PG, et al. Creation and Implementation of a Large-Scale Geriatric Interprofessional Education Experience. Curr Gerontol Geriatr Res. 2020;2020:3175403. Published 2020 Jul 25. doi:https://doi.org/10.1155/2020/3175403

51. Lee MY, Soriano RP, Fallar R, Ramaswamy R (2020) Assessment of medication management competency among medical students using standardized patients. J Am Geriatr Soc 68(3):E4-E6. https://doi.org/10.1111/jgs.16345

52. Hawley CE, Triantafylidis LK, Phillips SC, Schwartz AW. Brown Bag Simulation to Improve Medication Management in Older 
Adults. MedEdPORTAL. 2019;15:10857. Published 2019 Nov 22. doi:https://doi.org/10.15766/mep_2374-8265.10857

53. Ramaswamy R (2013) How to teach medication management: a review of novel educational materials in geriatrics. J Am Geriatr Soc 61(9):1598-1601. https://doi.org/10.1111/jgs.12404

54. Nussbaum SE, Oyola S, Egan M et al (2019) Incorporating older adults as "trained patients" to teach advance care planning to third-year medical students. Am J Hosp Palliat Care 36(7):608615. https://doi.org/10.1177/1049909119836394

55. Lucchetti ALG, Duarte BSVF, de Assis TV, Laurindo BO, Lucchetti G (2019) Is it possible to teach geriatric medicine in a stimulating way? measuring the effect of active learning activities in Brazilian medical students. Australas J Ageing 38(2):e58-e66. https://doi.org/10.1111/ajag.12626

56. Otsuka H, Kondo K, Ohara Y et al (2016) An inter- and intraprofessional education program in which dental hygiene students instruct medical and dental students. J Dent Educ 80(9):1062-1070

57. Farrell TW (2012) Review of "depression in the elderly-simulated patient small group activity." J Am Geriatr Soc 60(1):142-144. https://doi.org/10.1111/j.1532-5415.2011.03760.x

58. Nguyen AL, Duthie EA, Denson KM, Franco J, Duthie EH (2013) Positioning medical students for the geriatric imperative: using geriatrics to effectively teach medicine. Gerontol Geriatr Educ 34(4):342-353. https://doi.org/10.1080/02701960.2013.809714

59. Sehgal M, Syed Q, Callahan KE, et al. Introducing Aquifer Geriatrics, the American Geriatrics Society National Online Curriculum [published correction appears in J Am Geriatr Soc. 2019 Oct;67(10):2216]. J Am Geriatr Soc. 2019;67(4):811-817. doi:https://doi.org/10.1111/jgs.15813

60. Wu BJ, Honan L, Tinetti ME, Marottoli RA, Brissette D, Wilkins KM (2021) The virtual 4Ms: A novel curriculum for first year health professional students during COVID-19. J Am Geriatr Soc 69(6):E13-E16. https://doi.org/10.1111/jgs.17185

61. Neumann-Podczaska A, Seostianin M, Madejczyk K, et al. An Experimental Education Project for Consultations of Older Adults during the Pandemic and Healthcare Lockdown. Healthcare (Basel). 2021;9(4):425. Published 2021 Apr 6. https://doi.org/ 10.3390/healthcare9040425

62. Mehta CM. Flipping Out and Digging in: Combining the Flipped Class and Project-Based Learning to Teach Adult Development. Int J Aging Hum Dev. 2020;91(4):362-372. https://doi.org/10. 1177/0091415020919997

63. Granero Lucchetti AL, Ezequiel ODS, Oliveira IN, MoreiraAlmeida A, Lucchetti G (2018) Using traditional or flipped classrooms to teach "Geriatrics and Gerontology"? Investigating the impact of active learning on medical students' competences. Med Teach 40(12):1248-1256. https://doi.org/10.1080/0142159X. 2018.1426837

64. Laks J, Wilson LA, Khandelwal C, Footman E, Jamison M, Roberts E (2016) Service-learning in communities of elders (SLICE): development and evaluation of an introductory geriatrics course for medical students. Teach Learn Med 28(2):210-218. https:// doi.org/10.1080/10401334.2016.1146602

65. Gubner J, Smith AK, Allison TA (2020) Transforming undergraduate student perceptions of Dementia through music and filmmaking. J Am Geriatr Soc 68(5):1083-1089. https://doi.org/10. 1111 /jgs. 16418

66. Ferguson CC, Figy SC, Manley NA. Nursing Home Education During the COVID-19 Pandemic. J Med Educ Curric Dev. 2021;8:2382120521997096. Published 2021 Feb 23. https://doi. org/10.1177/2382120521997096

67. Jeste DV, Avanzino J, Depp CA et al (2018) Effect of short-term research training programs on medical students' attitudes toward aging. Gerontol Geriatr Educ 39(2):214-222. https://doi.org/10. 1080/02701960.2017.1340884
68. Wilson LA, Gilliam MA, Richmond NL, Mournighan KJ, Perfect CR, Buhr GT. Geriatrics Scholarly Concentration Programs Among U.S. Medical Schools. J Am Geriatr Soc. 2020;68(9):2117-2122. https://doi.org/10.1111/jgs.16673

69. LoFaso VM, Breckman R, Capello CF, Demopoulos B, Adelman RD (2010) Combining the creative arts and the house call to teach medical students about chronic illness care. J Am Geriatr Soc 58(2):346-351. https://doi.org/10.1111/j.1532-5415.2009.02686.x

70. Kanter SL (2012) The nursing home as a core site for educating residents and medical students. Acad Med 87(5):547-548. https:// doi.org/10.1097/ACM.0b013e3182557445

71. Fisher JM (2016) "The poor historian": Heart sink? Or time for a re-think? Age Ageing 45(1):11-13. https://doi.org/10.1093/ageing/afv169

72. Lubimir KT, Wen AB (2011) Towards cultural competency in endof-life communication training. Hawaii Med J 70(11):239-241

73. Edirne T, Kutlu M, Özhan B (2016) Tip fakultesi ikinci sinif ogrencilerinin yaslanma ve yaslilik egitimi hakkindaki gorusleri: Niteliksel bir calisma. Turk Geriatri Dergisi 19(2):122-127

74. Perni S, Pollack LR, Gonzalez WC, Dzeng E, Baldwin MR. Moral distress and burnout in caring for older adults during medical school training. BMC Med Educ. 2020;20(1):84. Published 2020 Mar 23. https://doi.org/10.1186/s12909-020-1980-5

75. Camp ME, Jeon-Slaughter H, Johnson AE, Sadler JZ (2018) Medical student reflections on geriatrics: moral distress, empathy, ethics and end of life. Gerontol Geriatr Educ 39(2):235-248. https://doi.org/10.1080/02701960.2017.1391804

76. Meiboom AA, de Vries H, Hertogh CM, Scheele F. Why medical students do not choose a career in geriatrics: a systematic review. BMC Med Educ. 2015;15:101. Published 2015 Jun 5. https://doi. org/10.1186/s12909-015-0384-4

77. Bagri AS, Tiberius R (2010) Medical student perspectives on geriatrics and geriatric education. J Am Geriatr Soc 58(10):1994 1999. https://doi.org/10.1111/j.1532-5415.2010.03074.x

78. Recommended Curriculum in Geriatric Medicine for Medical Undergraduates. The British Geriatrics Society (2013). https:// www.bgs.org.uk/resources/the-bgs-recommended-curriculumin-geriatric-medicine-for-medical-undergraduates (accessed 04 August 2021)

79. Ng B, Duong M, Lo S, Le Couteur D, Hilmer S. Deprescribing perceptions and practice: Reported by multidisciplinary hospital clinicians after, and by medical students before and after, viewing an e-learning module [published online ahead of print, 2021 Mar 11]. Res Social Adm Pharm. 2021;S1551-7411(21)00106-6. https://doi.org/10.1016/j.sapharm.2021.03.002

80. AGS Choosing Wisely Workgroup (2013) American Geriatrics Society identifies five things that healthcare providers and patients should question. J Am Geriatr Soc 61(4):622-631. https://doi.org/ $10.1111 /$ jgs. 12226

81. AGS Choosing Wisely Workgroup (2014) American Geriatrics Society identifies another five things that healthcare providers and patients should question. J Am Geriatr Soc 62(5):950-960. https:// doi.org/10.1111/jgs. 12770

82. By the 2019 American Geriatrics Society Beers Criteria ${ }^{\circledR}$ Update Expert Panel. American Geriatrics Society 2019 Updated AGS Beers Criteria ${ }^{\circledR}$ for Potentially Inappropriate Medication Use in Older Adults. J Am Geriatr Soc. 2019;67(4):674-694. https://doi. org/10.1111/jgs. 15767

83. Pazan F, Weiss C, Wehling M; FORTA. The FORTA (Fit fOR The Aged) List 2018: Third Version of a Validated Clinical Tool for Improved Drug Treatment in Older People. Drugs Aging. 2019;36(5):481-484. https://doi.org/10.1007/s40266-019-00669-6

84. O'Mahony D, O'Sullivan D, Byrne S, O'Connor MN, Ryan C, Gallagher P. STOPP/START criteria for potentially inappropriate prescribing in older people: version 2 [published correction 
appears in Age Ageing. 2018 May 1;47(3):489]. Age Ageing. 2015;44(2):213-218. https://doi.org/10.1093/ageing/afu145

85. Seppala LJ, Petrovic M, Ryg J et al (2021) STOPPFall (screening tool of older persons prescriptions in older adults with high fall risk): a delphi study by the EuGMS task and finish group on fallrisk-increasing drugs. Age Ageing 50(4):1189-1199. https://doi. org/10.1093/ageing/afaa249

86. Ceccofiglio A, Fumagalli S, Mussi C et al (2020) Atrial fibrillation in older patients with syncope and Dementia: insights from the syncope and dementia registry. J Am Med Dir Assoc 21(9):12381242. https://doi.org/10.1016/j.jamda.2020.01.110

87. Antonelli Incalzi R, Bernabei R, Bonanni P et al (2020) Vaccines in older age: moving from current practice to optimal coveragea multidisciplinary consensus conference. Aging Clin Exp Res 32(8):1405-1415. https://doi.org/10.1007/s40520-020-01622-z

88. Pham H, Geraci SA, Burton MJ; CDC advisory committee on immunization practices. adult immunizations: update on recommendations. Am J Med. 2011;124(8):698-701. doi:https://doi.org/ 10.1016/j.amjmed.2010.07.032

89. Ahmad FB, Anderson RN (2021) The leading causes of death in the US for 2020. JAMA 325(18):1829-1830. https://doi.org/10. 1001/jama.2021.5469
90. Green ML (2001) Identifying, appraising, and implementing medical education curricula: a guide for medical educators. Ann Intern Med 135(10):889-896. https://doi.org/10.7326/0003-4819135-10-200111200-00009

91. https://www.nfu.nl/sites/default/files/2020-08/20.1577_Raamp lan_Artsenopleiding_-_maart_2020.pdf (accessed 04 August 2021)

92. Doraiswamy S, Jithesh A, Mamtani R, Abraham A, Cheema S (2021) Telehealth use in geriatrics care during the COVID-19 pandemic-a scoping review and evidence synthesis. Int J Environ Res Public Health 18(4):1755. https://doi.org/10.3390/ijerph1804 1755

93. Steinman MA, Perry L, Perissinotto CM (2020) Meeting the care needs of older adults isolated at home during the COVID-19 pandemic. JAMA Intern Med 180(6):819-820. https://doi.org/10. 1001/jamainternmed.2020.1661

Publisher's Note Springer Nature remains neutral with regard to jurisdictional claims in published maps and institutional affiliations.

\section{Authors and Affiliations}

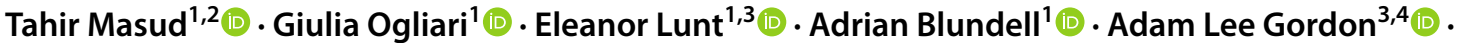

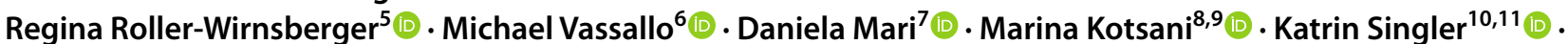 Roman Romero-Ortuno ${ }^{12}(1)$. Alfonso J. Cruz-Jentoft ${ }^{13}(1) \cdot$ Andreas E. Stuck $^{14}([)$}

Giulia Ogliari

giulia.ogliari@virgilio.it; Giulia.Ogliari1@nottingham.ac.uk

Tahir Masud

tahir.masud@nuh.nhs.uk

Eleanor Lunt

eleanor.lunt@nuh.nhs.uk; Eleanor.lunt@nottingham.ac.uk

Adrian Blundell

adrian.blundell@nuh.nhs.uk

Adam Lee Gordon

adam.gordon@nottingham.ac.uk

Regina Roller-Wirnsberger

regina.roller-wirnsberger@medunigraz.at

Michael Vassallo

michael.vassallo@uhd.nhs.uk

Daniela Mari

daniela.mari@unimi.it; daniela.mari46@gmail.com

Marina Kotsani

marinakots@gmail.com

Katrin Singler

katrin.singler@klinikum-nuernberg.de

Roman Romero-Ortuno

ROMEROOR@tcd.ie

Alfonso J. Cruz-Jentoft

alfonsojose.cruz@salud.madrid.org
Andreas E. Stuck

andreas.stuck@insel.ch

1 Department of Health Care for Older People (HCOP), Queen's Medical Centre, Nottingham University Hospitals NHS Trust, Derby Road, Nottingham NG7 2UH, Nottinghamshire, UK

2 Department of Geriatric Medicine, Odense University Hospital, Odense, Denmark

3 University of Nottingham, Nottingham, UK

4 University Hospitals of Derby and Burton NHS Foundation Trust, Derby, UK

5 Department of Internal Medicine, Medical University of Graz, Auenbruggerplatz 15, 8036 Graz, Austria

6 University Hospitals Dorset, Royal Bournemouth Hospital, Castle Lane East, Bournemouth BH7 7DW, UK

7 Laboratory of Geriatric and Oncologic Neuroendocrinology Research, IRCCS Istituto Auxologico Italiano, Milan, Italy

8 Université de Lorraine, CHRU-Nancy, Pôle "Maladies du Vieillissement, Gérontologie et Soins Palliatifs", 54000 Nancy, France

9 Working Group on the Development of Geriatric Medicine in Greece of the Hellenic Society for the Study and Research of Aging, 15342 Athens, Greece 
10 Department of Geriatric Medicine, Klinikum Nürnberg, Paracelsus Medical University Nürnberg, Nürnberg,

\section{Germany}

11 Institute for Biomedicine of Ageing, Friedrich-Alexander University Erlangen-Nürnberg, Nürnberg, Germany

12 Discipline of Medical Gerontology, School of Medicine, Trinity College Dublin, Dublin, Ireland
13 Hospital Universitario Ramón y Cajal (IRYCIS), Madrid, Spain

14 Department of Geriatrics, University of Bern, 3010 Bern, Switzerland 